\title{
Bacterial gene essentiality under modeled microgravity
}

2

3
Emanuel Burgos ${ }^{1}$, Madeline M. Vroom², Ella Rotman ${ }^{3 \S}$, Megan Murphy-Belcaster ${ }^{3 \dagger}$, Jamie S. Foster ${ }^{2}$, Mark J. Mandel ${ }^{1,3, *}$

${ }^{1}$ Department of Medical Microbiology and Immunology, University of Wisconsin-Madison, Madison, WI USA

${ }^{2}$ Department of Microbiology and Cell Science, Space Life Science Lab, University of Florida, Merritt Island, FL USA

${ }^{3}$ Department of Microbiology-Immunology, Northwestern University Feinberg School of Medicine, Chicago, IL USA

$\S$ Current Address: Department of Microbiology, University of Chicago, Chicago, IL USA

${ }^{\dagger}$ Current Address: University of Wisconsin-Madison School of Medicine and Public Health, Madison, WI USA

Short title: Vibrio fischeri modeled microgravity mutant analysis

Keywords: modeled microgravity, essential genes, symbiosis, Vibrio fischeri, Aliivibrio fischeri, Euprymna scolopes, INSeq, Tn-seq

* Correspondence to:

Mark J. Mandel

University of Wisconsin-Madison

Department of Medical Microbiology and Immunology 1550 Linden Drive

Madison, WI 53706

Phone: (608) 261-1170

Fax: (608) 262-8418

Email: mmandel@wisc.edu

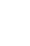




\section{ABSTRACT}

46 The health of eukaryotic hosts is tightly connected to relationships with symbiotic

47 microorganisms, yet how these relationships develop and evolve during long-duration spaceflight is not well understood. In this study, we asked what bacterial genes are required for growth under modeled, or simulated, microgravity conditions compared to normal gravity controls. To conduct this study, we focused on the marine bacterium Vibrio fischeri, which forms a monospecific symbiosis with the Hawaiian bobtail squid, Euprymna scolopes. The symbiosis has been studied during spaceflight and in ground-based modeled microgravity conditions. We employed a library of over 40,000 V. fischeri transposon mutants and compared the fitness of mutants in modeled microgravity compared to the gravity controls using transposon insertion sequencing (INSeq). We identified dozens of genes that exhibited fitness defects under both conditions, likely due to the controlled anaerobic environment, yet we identified relatively few genes with differential effects under modeled microgravity or gravity specifically: only mutants in $\operatorname{rod} A$ were more depleted under modeled microgravity, and mutants in 12 genes exhibited

59 greater depletion under gravity conditions. We additionally compared RNA-seq and INSeq data and determined that expression under microgravity was not predictive of the essentiality of a

61 given gene. In summary, empirical determination of conditional gene essentiality identifies few 


\section{IMPORTANCE}

67 There is substantial evidence that both the host immune system and microbial physiology are

68 altered during space travel. It is difficult to discern the molecular mechanisms of these

69 processes in a complex microbial consortium and during the short durations of experiments in

70 space. By using a model organism that is amenable to high-throughput genetic approaches, we

71 have determined that $V$. fischeri does not require a separate genetic repertoire for media growth

72 in modeled microgravity versus gravity conditions. Our results argue that future studies on how

73 this organism forms a specific and stable association with its animal host will not be confounded

74 by growth effects in the environment. The identification of similar genetic requirements under

75 modeled microgravity and gravity suggest that fitness pressures on microbiome growth in space

76 may be similar to those on Earth and may not negatively impact their animal hosts during long-

77 duration spaceflight. 


\section{INTRODUCTION}

83 During spaceflight, microbes--and microbe-host relationships--are altered, and understanding

84 the mechanisms of these effects are critical as people, plants, and animals spend more time in

85 space (1-7). To address this issue, experiments are needed to examine bacterial growth,

86 bacterial-host interactions, and host health. Although previous studies using both natural and

87 modeled microgravity conditions have resulted in a wide range of physiological and genetic

88 responses, most have primarily targeted pathogenic strains $(8,9)$. While fewer studies have

89 examined the effects of microgravity on beneficial microbes, there are recent studies that have

90 begun to examine this issue (4-6). Given the importance of beneficial microbes to host health,

91 we sought here to ask a fundamental question of what genes are required for bacterial growth in

92 microgravity.

93

94 Due to the number of logistical constraints in conducting spaceflight experiments, several

95 ground-based platforms exist to mimic the low-shear environment of microgravity (10). Rotating

96 High Aspect-Ratio Vessels (HARVs) represent one such platform; they mimic the low-shear fluid

97 conditions that occur at low Earth orbit, and have been used for decades to simulate

98 microgravity environments (11). As cells grow in the HARVs, the hydrodynamic forces within

99 each vessel offset the effects of gravity and the cells are essentially in "freefall" and maintained

100 in a constant suspension (Fig. 1). Bacterial strains grown in these low-shear modeled

101 microgravity (LSMMG) conditions can experience a wide range of different physiological 
responses, including increases in growth rates, biofilm formation, secondary metabolite

103 production, environmental stress responses, and antibiotic resistance $(6,12-16)$.

105 The model symbiosis of Vibrio fischeri colonization of the light organ of the Hawaiian bobtail

106 squid, Euprymna scolopes, has emerged as a valuable model to study the effects of

107 microgravity on microbiome assembly and function (1). The squid hatches each generation

108 without its bacterial partner, and then proceeds to harvest $V$. fischeri from the seawater (17).

109 The bacteria colonize the dedicated symbiotic light organ of the host, where bioluminescence

110 from the bacteria is projected downward and camouflages the host in the moonlight (18). This

111 system has been especially valuable to understand the molecular basis by which animals

112 acquire specific microbes from the environment. The bacteria are genetically manipulatable, and

113 the site of colonization can be imaged directly in live animals, enabling studies that have

114 revealed much of the molecular dialogue between the two partners (19-22). The specific

115 relationship--only $V$. fischeri, and only specific strains of $V$. fischeri, can colonize the squid host--

116 provides a strong model system to study animal-microbiome formation, development, and

117 evolution (17). Furthermore, the small size of the host animal and simplicity of the symbiosis has

118 contributed to the value of this system for studying microbiome formation during spaceflight (1,

$11923)$.

121 In this study, we take a complementary approach to previous work on bacterial gene expression

122 under simulated microgravity to ask what genes are required for survival under this condition. 
123 Our lab has previously published a study to globally identify $V$. fischeri genes that are essential,

124 and that are conditionally essential under specific environmental conditions (24). Here we apply

125 a similar global approach to determine what genes are required for bacterial growth under

126 simulated microgravity conditions to ascertain the overall impact that microgravity-like conditions

127 have on symbiont health and physiology.

\section{RESULTS}

131 A number of studies have examined differential-gene expression in beneficial microbes under

132 microgravity or simulated microgravity conditions, including in the marine bacterium $V$. fischeri

133 (6). The current study asks a distinct, yet related, question of what genes are differentially

134 required for growth under simulated microgravity conditions compared to a gravity control

135 condition. To identify mutants with a competitive growth defect in simulated microgravity, we

136 applied the transposon insertion sequencing (INSeq/Tn-seq) approach to $V$. fischeri strains

137 cultivated under HARV conditions in both the LSMMG and gravity positions (Fig. 1) (25, 26). We

138 started with a characterized mutant library of over 40,000 transposon mutants in $V$. fischeri

139 strain ES114 (24). The resulting “input” library was introduced into HARV vessels under either

140 LSMMG or normal gravity conditions $(1 \times g)$. We simultaneously examined the mutant library

141 grown in LSMMG and gravity control conditions after growth for approximately 15 generations,

142 and each resulting "output" pool of mutants was frozen. A total of six LSMMG biological

143 replicates and three gravity control replicates were compared to the input library. From each 
144 sample, DNA was isolated, from which INSeq libraries were constructed (26). The libraries were

145 sequenced on an Illumina HiSeq 2000 instrument, and the location of each transposon insertion

146 was mapped using the pyinseq Python package.

148 For each sample, we obtained between $6.65-8.18 \times 10^{6}$ Illumina reads (Table S1). We

149 observed similar numbers and patterns of unique transposon hits across the samples tested,

150 suggesting that the library did not undergo significant bottlenecks during the experiment (Table

151 S1). Next, for each sample, we examined the normalized transposon insertion counts (CPM;

152 counts-per-million Illumina reads) in each gene. We compared the similarity of these gene-level

153 counts across the samples in the analysis using pairwise correlation analysis. All pairwise

154 comparisons had a high level of similarity (Spearman $R^{2}>0.95$ ), and the HARV-grown samples

155 were clearly distinguishable from the input libraries (Fig. 2). Examination of the heat map

156 suggested little overall differentiation between the LSMMG and gravity samples that were

157 otherwise grown similarly. We proceeded to compare individual genes that were depleted under

158 LSMMG, gravity, or both conditions. To identify genes that had significant differential depletion

159 under modeled microgravity we used DESeq2 to calculate the median representation of each

160 mutant in the output LSMMG or gravity pools, and plotted those values compared to the input

161 pool. We focused our analysis on genes that were depleted at least 2-fold in the different

162 conditions. Genes that did not meet these criteria, genes that were poorly represented in the

163 input pool, and genes for which a previous study suggested that mutants impaired bacterial

164 growth were excluded from further analyses (Fig. 3; open black circles). A total of 109 genes 

genes, most were similarly depleted under both conditions. However, there were genes in this

167 group that had a $\geq 2$-fold difference in one condition (LSMMG or gravity) relative to the other:

168 this includes 10 genes more depleted under gravity and one gene $(\operatorname{rod} A)$ more depleted under

169 LSMMG. Furthermore, there were two genes in the analysis that were significantly depleted $(p<$

1700.05 from DESeq2 analysis) under gravity conditions and not under LSMMG conditions (flgD,

$171 \mathrm{rfaD}$ ). There were no genes that were only significantly depleted under LSMMG conditions.

173 The above results were derived from an analysis of complex mutant pools with $>40,000$

174 mutants. We therefore sought to determine whether we would observe the same behavior using

175 one-versus-one competitions between defined mutant strains and the parental strain. We

176 proceeded to isolate mutant strains that had a depletion from the INSeq analysis, as well as

177 mutants in two control genes that were not depleted under either condition (brnQ and $n h a R)$.

178 Each defined mutant strain was grown in culture, then competed in the HARVs against the

179 parental strain that carries the LacZ-expressing plasmid pVSV103 (27). The input and output

180 pools from each experiment were plated onto LBS-Xgal medium, and the ratio of blue:white

181 colonies in the samples were calculated. A competitive index was calculated to determine the

182 fitness of each mutant under each condition. Plotted in Figure 4 are the results of this analysis.

183 Although some differences were observed between the massive INSeq competition and the

184 defined one-vs-one competitions, there was strong concordance between the INSeq and

185 defined competition results. All of the genes for which mutants were significantly depleted under 
186 INSeq were also substantially depleted in the defined competitions, and the control mutants

187 exhibited no substantial depletion. Therefore, we conclude that the INSeq analysis can reliably

188 predict conditional gene requirements in the HARV environment.

190 We recently examined bacterial genes for which mRNA levels are induced in the modeled

191 microgravity condition, compared to gravity controls (6). We analyzed our current study of gene

192 requirement (i.e., INSeq) with the previous dataset on gene expression (i.e., RNA-Seq) to ask

193 whether there is a correlation between gene requirement and gene expression. As shown in

194 Figure 5A, there was no significant correlation between gene requirement and transcript

195 induction (Pearson $\mathrm{R}^{2}=0.08$ ). Our data above suggest that the HARV platform may play a

196 more significant role in shaping mutant communities than the specific LSMMG or gravity

197 conditions. Therefore, we asked whether genes required in the HARV are also induced in the

198 HARV, when normalized to non-HARV samples. For our INSeq data, we normalized to the input

199 sample that did not experience the HARV condition, and for RNA-Seq we normalized to

200 published data on culture-grown V. fischeri (28). As shown in Figure 5B-C, there is similarly a

201 lack of overall correlation between the gene expression and gene requirement $\left(\right.$ Pearson $\mathrm{R}^{2}=$

$2020.18,0.11$ for Fig. 5B, 5C, respectively). Therefore, we conclude that gene requirement in the

203 HARV cannot be predicted from transcriptome induction data, emphasizing the need for

204 empirical determination of gene essentiality. 


\section{DISCUSSION}

This study provides a global view of $V$. fischeri genes that are required for growth in conditions

210 that simulate microgravity. Given the prominence of modeled microgravity platforms, such as

211 HARVs, in examining the impact of spaceflight on animal-microbe interactions, a motivation for

212 this work was to understand how the basic requirements for bacterial survival and growth are

213 altered during growth in the HARV platforms. A surprising finding was that there is little

214 difference in gene requirement under these conditions, despite dramatic differences in gene

expression. These findings, and their implications, are discussed in greater detail below.

217 The global data provided by INSeq, along with the comparison of the INSeq data with results

218 from defined mutants, provided sensitive internal controls to examine growth in multiple HARV

219 samples. Overall, the data we obtained from HARV samples was highly consistent. As shown in

220 the heat map in Figure 2, the high correlation of INSeq replicates within a treatment (e.g., for

221 LSMMG samples) argues that there was no substantial bottleneck during inoculation or growth

222 in the HARVs. Furthermore, strong correlation between INSeq results and the results with

223 defined mutants (Fig. 4) provides support that the global data are representative of gene-level

224 data. In fact, the consistency we observed between vessel replicates was also observed

225 between HARV LSMMG and gravity samples. The heat map in Fig. 2 coupled with the tight

226 correlation of the samples in Figure 3 (Pearson $\left.R^{2}=0.96\right)$ illustrate that there was little variation

227 observed between the LSMMG and gravity conditions. A striking consistency between genes 
required for bacterial growth under gravity and those required for growth under modeled

229 microgravity is the major finding from this study. As the $V$. fischeri system is used for more

230 extensive research on microgravity, this result indicates there will not be a confounding effect of

231 genes that are simply required for bacterial growth under microgravity. Put another way, in the

232 future, if genes are identified that are required for colonization under microgravity, they are likely

233 to be required specifically for interaction with the animal host, and not simply for growth under

234 this altered gravity condition. Our findings, in concert with previous studies showing limited

235 changes in gene expression during spaceflight, suggest that spaceflight missions will have

236 minimal negative consequences on the microbiome.

238 Despite the overall patterns of concordance between LSMMG and gravity, there were genes for

239 which we observed differential effects between the two conditions, as plotted in Figure 3 and

240 detailed in Table S3. For example, depletion in rodA ( $m r d B)$ under both LSMMG and gravity

241 was observed, yet the gene was more significantly depleted under LSMMG. RodA is a SEDS-

242 family peptidoglycan polymerase that has multiple effects on bacterial cell shape and division

243 (29). This result suggests that differences in bacterial shape under the two different conditions

244 may impact the genetic requirement for $\operatorname{rod} A$, though we note that its absence does affect

245 growth under both regimes. We additionally identified a number of genes with mutants depleted

246 under both conditions but that were more significantly depleted under gravity (Figure 3, filled red

247 dots). Notably, multiple genes for the F0F1-ATPase were depleted under both conditions, but

248 more so under gravity. Interestingly, prior work in Escherichia coli demonstrated that a similar 
249 set of genes were essential for aerobic growth in minimal glycerol media, even though the

250 metabolic model used predicted that they would not be required (30). Together with our results,

251 this suggests that this subset of genes (atpA, atpB, atpC, atp $F)$ may perform a function separate

252 from the role in ATP synthesis. Finally, there were two genes for which mutants exhibited

253 significant depletion under gravity but not LSMMG: flgD (encoding the hook capping protein

254 FlgD) and $r f a D$ (encoding the LPS biosynthesis enzyme ADP-L-glycero-D-mannoheptose 6-

255 epimerase). Both genes affect the outer surface of the bacteria, and consistent with the rodA

256 results above, support the idea that the bacterial envelope is most susceptible to differential

257 effects of gravity.

259 It is also important to note that we observed dozens of genes for which mutants exhibited similar

260 depletion under both LSMMG and gravity conditions (Fig. 3; black filled dots). We note that

261 significant growth defects for mutants in these genes was not observed during 15 generations of

262 growth in LBS medium under aerobic conditions (24). Therefore, these genes are likely required

263 for robust growth in the HARV, but not for growth in LSMMG versus gravity. Given the

264 anaerobic environment of the HARV, it seems likely that many of these genes may be required

265 for optimal growth under anaerobic conditions. This hypothesis is supported by the presence of

266 four genes of the $\mathrm{Na}^{+}$-translocating $\mathrm{NADH}$ :quinone oxidoreductase (nqrA, nqrB, nqrD, nqrE),

267 which, in the related species $V$. cholerae, conducts $90 \%$ of the membrane NADH

268 dehydrogenase activity under anaerobic conditions $(31,32)$. We also note the presence of some

269 genes that are required for robust symbiosis in this category, including degS, dnaJ, and ompU 
$270(24,33)$. Given that mutants in these genes exhibited growth defects in both LSMMG and

271 gravity conditions in the HARVs, our results suggest that colonization in the HARV may proceed

272 differently than under standard laboratory conditions. Furthermore, we speculate that these

273 genes may play a role in $V$. fischeri growth under anaerobic conditions.

275 A possible limitation of the current study is that the transposon library used was built on agar

276 plates in a standard microbiology laboratory; i.e., under normal gravity conditions. However,

277 were this a major limitation, then in Figure 3 we would have observed a large number of

278 mutants with no defect in gravity but with a defect in LSMMG (e.g., in the top left of the figure).

279 Not only did we not observe a substantial number of such genes, but they were outnumbered by

280 the genes that fell in the bottom right. Therefore, we can conclude that the origination of the

281 library in the gravity condition did not impair our ability to investigate this question.

283 We provide a comparison of our INSeq data with previously published RNA-Seq data. As shown

284 in Figure 5, there is little correlation between gene requirement (INSeq) and gene expression

285 (RNA-Seq). It is important to consider both gene requirement and gene expression, as genes

286 that are not induced in a condition may nonetheless be required for growth and/or survival. For

287 example, a gene that is expressed at a constant level under two conditions may be required for

288 survival in only one of those conditions. Broader analysis comparing gene requirement and

289 expression have demonstrated that these categories are often unlinked (34). Our results argue 
that genes that are induced in simulated microgravity are not preferentially required for bacterial

291 growth under these conditions.

293 Overall, this work establishes which genes were impacted by growth in LSMMG, gravity, or the

294 HARV environment generally. We additionally determined that microgravity-induced transcripts

295 do not predict which genes are conditionally essential under this condition. Finally, we

296 demonstrated that the HARV environment is amenable to high-throughput genetic experiments

297 and was reproducible within treatments. This study, therefore, provides a solid foundation for

298 future studies that seek to identify the genetic basis by which bacteria and animals form specific,

299 robust interactions under conditions of reduced gravity.

301 MATERIALS AND METHODS

303 Media and growth conditions. V. fischeri strains were grown at $25^{\circ} \mathrm{C}$ in Luria-Bertani salt

304 (LBS) medium (per liter, $10 \mathrm{~g}$ Bacto-tryptone, $5 \mathrm{~g}$ yeast extract and $20 \mathrm{~g} \mathrm{NaCl}, 50 \mathrm{ml} 1 \mathrm{M}$ Tris

305 buffer, $\mathrm{pH} 7.5$, in distilled water). When appropriate, antibiotics or supplements were added to

306 media at the following concentrations: erythromycin, $5 \mu \mathrm{g} / \mathrm{ml}$; chloramphenicol, $5 \mu \mathrm{g} / \mathrm{ml}$; X-gal

307 (5-bromo-4-chloro-3-indolyl- $\beta$-D-galactopyranoside), $80 \mu \mathrm{g} / \mathrm{ml}$. Growth media were solidified

308 with $1.5 \%$ agar as needed. 
310 Preparation of input and output samples from HARV growth. The Lib04 library of pMarVF1

311 mariner transposon insertions in MJM1100 (ES114) was described previously (24). Twenty-five

312 microliters of the library (approximately $2 \times 10^{8} \mathrm{CFU}$ ) were inoculated into $5 \mathrm{ml}$ LBS, and grown

313 at $26{ }^{\circ} \mathrm{C}$ for approximately $5 \mathrm{~h}$, to an $\mathrm{OD}_{600}$ of approximately 0.3 . Aliquots $(552 \mu \mathrm{l})$ of culture was

314 transferred to each of eight flasks containing $100 \mathrm{ml}$ LBS (i.e., $2^{7.5}$-fold dilution) and mixed well;

315 an additional $500 \mu \mathrm{l}$ of input culture was frozen in $17 \%$ glycerol $(\mathrm{v} / \mathrm{v})$ as the input sample. From

316 each flask, $50 \mathrm{ml}$ was inoculated into each HARV: LSMMG vessels A, B, C, and D; and gravity

317 vessels A, B, C, and D. Each vessel D was used to monitor growth rate. Samples were grown

318 for approximately $5.25 \mathrm{~h}$ to an $\mathrm{OD}_{600} \leq 0.3$; diluted another $2^{7.5}$-fold; grown to a final $O D_{600}$ of

319 approximately 0.3 , then frozen as the 15 -generation output samples. In some cases, HARV

320 vessels leaked or had significantly reduced growth rate, and those samples were excluded from

321 further analysis.

323 INSeq sample preparation. DNA from the input and output samples was prepared using the

324 MoBio Biofilm Isolation Kit (Carlsbad, CA). Samples were prepared for INSeq analysis using the

325 protocol of Goodman et al. (26), with double the BioSamA primer concentration. Samples were

326 submitted to the Tufts University Core Facility (TUCF) for sequencing on the Illumina HiSeq

3272500 (single-end 50 bp reads). The resulting reads were deposited at NCBI SRA under

328 accession number SRR12394639. 
330 Bioinformatic Analysis of INSeq data. Each sample was processed using the bioinformatic

331 software pyinseq (https://github.com/mjmlab/pyinseq, v0.2.0) to quantify transposon insertions

332 and then analyzed using Python visualization and statistical modules. Pyinseq starts by

333 demultiplexing the raw reads using a barcode index and then maps them to the reference

334 genome (ES114v2: CP000020.2, CP000021.2, CP000022.1) using the short-read aligner

335 software Bowtie (35) with parameters that allow a single base-pair mismatch. Reads with

336 multiple alignments (e.g., to the 12 semi-redundant rRNA operons and in tRNA genes) were

337 excluded. The output alignment files were used to quantify the frequency of reads at each

338 transposon insertion site (TA dinucleotides, for the mariner transposon). Transposon-insertion

339 sites were analyzed if they contain a minimum of three reads and have reads from both the left

340 and right flanking sequence (with a maximum difference of 10-fold abundance for one side over

341 the other). For each sample, a T50 value was calculated, which is defined as the minimum

342 number of transposon insertion sites that account for $50 \%$ of the reads in that sample. Gene-

343 level analysis consolidates the site-level data for insertions that fall in the 5 '-most $90 \%$ of each

344 gene (-d parameter of 0.9). The pyinseq summary gene table (Table S2) was further analyzed

345 using pandas, a python module for manipulating large datasets $(36,37)$. In addition, pandas

346 was used to calculate spearman correlation values of each pairwise sample comparison. The

347 technical averages for each sample was further analyzed using DESeq2, an R package that

348 normalizes the dataset and performs appropriate statistical tests on high-throughput count data

349 that does not follow a normal distribution such as INSeq (38). DESeq2 was used to estimate the 
350 library size, normalize sequencing depth of samples, and calculate variation of each gene for

351 statistical testing.

Transformation of VFS into MJM1100 background. The VFS mutant collection was

354 assembled by sequencing random pEVS170 transposon insertions into ES114 (24, 39). Mutant

355 alleles were moved into the MJM1100 background using transformation under tfox induction

356 (40). Selected VFS strains grown on LBS plates were verified with PCR amplification using

357 locus-specific primers and transposon-anchored primers MJM-127 (pEVS170 transposon) or

358 SamA (pMarVF1 transposon) (Table 2). Recipient strain MJM1538 (MJM1100 carrying

359 pLostfoX) was grown overnight in $3 \mathrm{ml}$ of LBS containing $2.5 \mu \mathrm{g} / \mathrm{ml}$ chloramphenicol and then

360 subcultured 1:100 into $3 \mathrm{ml}$ of Tris Minimal with $N$-acetylglucosamine (GlcNac) for overnight

361 growth. The recipient was then subcultured 1:50 into fresh Tris-Minimal-GlcNac-Cam with

362 aeration until the $\mathrm{OD}_{600}$ reached $0.2-0.3$, when $500 \mu \mathrm{l}$ of recipient culture was incubated with 2.4

$363 \mu \mathrm{g}$ of VFS donor DNA (prepared with the Qiagen Blood and Tissue kit, Gram-negative bacteria

364 protocol), followed by a brief vortex, and then static incubation at room temperature for $30 \mathrm{~min}$.

365 One $\mathrm{ml}$ of LBS was added to culture, transferred to a glass culture tube, and incubated

366 overnight with aeration. The culture was spun down ( $8000 \times g, 1 \mathrm{~min}), 900 \mu \mathrm{l}$ of supernatant

367 was removed, and the pellet was resuspended in the remaining $\sim 100 \mu \mathrm{l}$ of LBS. Aliquots $(50 \mu \mathrm{l})$

368 of each sample were plated on LBS-erythromycin (LBS-Erm; $5 \mu \mathrm{g} / \mathrm{ml}$ ) and three candidates

369 were selected. Colonies were restreaked on LBS-Erm plates and then patched on selective

370 media to check for absence of pLostfoX (LBS-Cam ${ }^{S}$ ) and the presence of the transformed DNA 
371 (LBS-Erm $\left.{ }^{\mathrm{R}}\right)$. Transformation was verified with PCR amplification using primers that target the

372 transposon junction and the gene target (Table 2).

373

374 Competitions of individual gene mutants with a marked parental strain in the HARVs.

375 The competitive fitness of seven transposon mutants (Table 1) was evaluated in one-

376 on-one competition assays against the LacZ-expressing wild type, MJM1575, in the

377 HARV vessels. Overnight cultures of each strain were prepared in LBS with shaking at

$37825^{\circ} \mathrm{C}$ and diluted 1:100 in fresh medium the following morning. After $2 \mathrm{~h}$ of growth at 25

$379{ }^{\circ} \mathrm{C}$ with shaking, the mutant and wild-type subcultures were normalized by $\mathrm{OD}_{600}$ and

380 combined at a 1:1 ratio in fresh LBS. The resultant starting culture was subsequently

381 loaded into the HARV vessel. At this time, two samples of the mixed input culture were

382 collected: the first was preserved in $33 \%$ glycerol $(\mathrm{v} / \mathrm{v})$ and stored at $-80{ }^{\circ} \mathrm{C}$ for later

383 analysis, whereas the second was serially diluted in PBS (pH 7.0) and plated on LBS-

384 Xgal agar $(2 \mathrm{mg} / \mathrm{ml})$ to reveal the starting ratio of mutant:control, based on the

385 proportion of white-to-blue colonies, as previously described (24). In the HARVs, the

386 mutant and marked wild type were grown in competition with each other under LSMMG

387 or gravity conditions for approximately 10 generations at $25^{\circ} \mathrm{C}$ and $13 \mathrm{rpm}$. After 10

388 doublings, which was determined by $\mathrm{OD}_{600}$, samples of the output cultures were

389 preserved in $33 \%$ glycerol (v/v) and stored at $-80^{\circ} \mathrm{C}$. The input and output samples

390 were plated on LBS-Xgal agar to calculate the competitive index for each sample. The 
391 competitive index is equal to the $\log _{10}$ value of the mutant/wild type ratio after

392 competition normalized to its measured ratio at the beginning of the competition.

394 DATA AVAILABILITY

395 Illumina data for the INSeq reads are available at NCBI SRA, Accession number

396 SRR12394639. 
TABLES

Table 1. V. fischeri strains used in this study.

\begin{tabular}{|l|l|l|}
\hline Strain & Genotype & Reference/Source \\
\hline MJM1100 & Wild-type ES114 & $(41,42)$ \\
\hline MJM1538 & MJM1100/pLostfoX & $(43)$ \\
\hline MJM1575 & MJM1100/pVSV103 & $(27,44)$ \\
\hline MJM3801 & MJM1100 sspA::Tnerm (transformed from VFS025D03) & This work \\
\hline MJM3802 & MJM1100 mukB::Tnerm (transformed from VFS001A10) & This work \\
\hline MJM3804 & MJM1100 ruvB::Tnerm (transformed from VFS020B09) & This work \\
\hline MJM3805 & MJM1100 brnQ::Tnerm (transformed from VFS022E03) & This work \\
\hline MJM3807 & MJM1100 nhaR::Tnerm (transformed from VFS022G01) & This work \\
\hline MJM3808 & MJM1100 ubiH::Tnerm (transformed from MJM1976) & This work \\
\hline MJM3809 & MJM1100 hs/O::Tnerm (transformed from MJM1628) & This work \\
\hline
\end{tabular}


Table 2. Oligonucleotide primers

\begin{tabular}{|c|c|c|}
\hline Name & Sequence $\left(5^{\circ}-3^{\prime}\right)$ & Source \\
\hline MJM-127 & ACAAGCATAAAGCTTGCTCAATCAATCACC & (45) \\
\hline SamA & AAGCAGAAGACGGCATACGAAGACC & (26) \\
\hline EB01 $(\operatorname{ssp} A)$ & AACGGAGCTAAGTAACAATCCACT & This work \\
\hline EB02 (mukB) & CACCTAGTGTATCAGCAAGACCTT & This work \\
\hline EB03 (ruvB) & TCACTCGCTTTCAATTAACTCAGC & This work \\
\hline EB06 (brnQ) & CAGCAACTTTCGCAGCATCTAATA & This work \\
\hline EB08 (nhaR) & TTGTAAGTCCATATAGACGCCCAC & This work \\
\hline EB10 (hs/O) & AACATGGTTGATGGAGGTAAAGTT & This work \\
\hline EB11 (ubiH) & CAAATTCAATCTTAGCAAAGCTGTC & This work \\
\hline
\end{tabular}




\section{FIGURES}

413 Figure 1. Experimental setup for bacterial mutant enrichment in HARV vessels to model

414 microgravity (LSMMG) and to have the control gravity condition. INSeq libraries were

415 grown in HARV vessels that can simulate microgravity when placed perpendicular or gravity

416 when horizontal. Mutants exhibited either no defects in either condition, or exhibited (1) a growth

417 defect in both conditions, (2) LSMMG defect, (3) or a gravity-specific defect.

Figure 2. Pairwise correlation between samples revealed a clear difference between input

samples and output samples from the HARV conditions. Spearman correlations between

421 samples, in which the normalized transposon insertion counts in each gene were compared.

422 Input replicates were the original INSeq library grown for inoculation into the HARV, and low-

423 shear modeled microgravity (LSMMG) and normal gravity replicates were outputs from the

424 respective HARV-grown experiments.

Figure 3. Mutant behavior under LSMMG or gravity revealed fitness in each HARV

427 condition, normalized to the input transposon sequencing library. A) Comparison scatter

428 plot of microgravity (x-axis) and gravity (y-axis) Log(Fold-Change) values. Counts for each gene

429 for each replicate were normalized and used to calculate Log10(Fold-Change) values as

430 described in Materials and Methods. Genes that were poorly represented in the input pool did

431 not exhibit significant depletion, or were previously determined to be growth deficient in LBS 
432

433

434

435

436

437 shown as open black circles.

438

439

440

441

442

443

444

445

446

447

448

449

450

451

452

medium were designated as open black circles. Filled black circles are genes that were

significantly ( $p$-value $<0.05$ ) depleted 2-fold change under both simulated microgravity and

gravity conditions. Genes that are filled red were significant in both conditions but more depleted

under gravity, whereas open red circles are exclusively significant in gravity. Filled blue genes

are significant in both but more depleted under simulated microgravity. Remaining genes are

Figure 4. Competition of defined mutants provided validation of mutant fitness from

within the complex INSeq library. Mutants were competed against wild-type $V$. fischeri under

simulated microgravity and gravity using the HARV vessels. Dots represent fold-change for 1:1

competition of mutant vs. marked parental strain (MJM1575).

Figure 5.Gene expression (RNA-Seq) does not predict conditional gene requirement

(INSeq) under LSMMG conditions. INSeq (y-axis) and RNA-Seq (x-axis) were compared by

using log-normalized fold-change values for different experimental conditions. A) INSeq

(LSMMG/Gravity) was compared to a previously published RNA-Seq (LSMMG/Gravity) under

HARV conditions and had an $R^{2}$ of 0.08 . We also calculated fold-changes for RNA-Seq HARV

conditions using a dataset from SWT medium. B) INSeq (Gravity/Input) were compared to RNA-

Seq (Gravity/SWT) and had an $\mathrm{R}^{2}$ of 0.18 . C) INSeq (LSMMG/Input) was compared to RNA-

Seq (LSMMG/SWT) and had an $\mathrm{R}^{2} 0.11$. 


\section{SUPPLEMENTAL DATA}

454 The file Supplemental_Tables.xlsx includes the following tables:

Table S1: INSeq sample details

Table S2: Summary gene table output from pyinseq

Table S3: List of genes depleted as shown in Figure 3

\section{ACKNOWLEDGMENTS}

461 We acknowledge Cheryl Whistler and Randi Foxall for VFS Library mutants and A. Murat Eren

462 and his laboratory for technical advice and mentorship. Funding was provided by NASA's Illinois

463 Space Grant Consortium Research Seed Grant (M.J.M.), NIGMS R35 GM119627 (M.J.M.), an

464 American Society for Microbiology Undergraduate Research Fellowship (E.B.), and the McNair

465 Scholars Program (E.B.). The project was also supported in part by a NASA Space Biology

466 award 80NSSC18K1465 (J.S.F.). 


\section{REFERENCES}

471 1. Foster JS, Khodadad CLM, Ahrendt SR, Parrish ML. 2013. Impact of simulated

472 microgravity on the normal developmental time line of an animal-bacteria symbiosis. Sci

$473 \quad$ Rep 3:srep01340.

474 2. Voorhies AA, Lorenzi HA. 2016. The Challenge of Maintaining a Healthy Microbiome during

$475 \quad$ Long-Duration Space Missions. Frontiers in Astronomy and Space Sciences 3:23.

476 3. Casaburi G, Goncharenko-Foster I, Duscher AA, Foster JS. 2017. Transcriptomic changes

477 in an animal-bacterial symbiosis under modeled microgravity conditions. Sci Rep 7:46318.

478 4. Castro-Wallace S, Stahl S, Voorhies A, Lorenzi H, Douglas GL. 2017. Response of Lactobacillus acidophilus ATCC 4356 to low-shear modeled microgravity. Acta Astronaut 139:463-468.

5. Shao D, Yao L, Riaz MS, Zhu J, Shi J, Jin M, Huang Q, Yang H. 2017. Simulated microgravity affects some biological characteristics of Lactobacillus acidophilus. Appl Microbiol Biotechnol 101:3439-3449.

6. Duscher AA, Conesa A, Bishop M, Vroom MM, Zubizarreta SD, Foster JS. 2018. modeled microgravity. npj Microgravity 4:25.

487 7. Garrett-Bakelman FE, Darshi M, Green SJ, Gur RC, Lin L, Macias BR, McKenna MJ, 488 Meydan C, Mishra T, Nasrini J, Piening BD, Rizzardi LF, Sharma K, Siamwala JH, Taylor L, 489 Vitaterna MH, Afkarian M, Afshinnekoo E, Ahadi S, Ambati A, Arya M, Bezdan D, Callahan 490 CM, Chen S, Choi AMK, Chlipala GE, Contrepois K, Covington M, Crucian BE, De Vivo I, 
Dinges DF, Ebert DJ, Feinberg JI, Gandara JA, George KA, Goutsias J, Grills GS, Hargens

AR, Heer M, Hillary RP, Hoofnagle AN, Hook VYH, Jenkinson G, Jiang P, Keshavarzian A,

Zhang J, Ziegler MG, Zwart SR, Charles JB, Kundrot CE, Scott GBI, Bailey SM, Basner M,

Feinberg AP, Lee SMC, Mason CE, Mignot E, Rana BK, Smith SM, Snyder MP, Turek FW. spaceflight. Science 364 .

8. Chang D, Zhu Y, An L, Liu J, Su L, Guo Y, Chen Z, Wang Y, Wang L, Wang J, Li T, Fang

BMC Microbiol 13:304.

9. Wilson JW, Ott CM, Quick L, Davis R, Höner zu Bentrup K, Crabbé A, Richter E, Sarker S, Buchanan K, Morici L, McCracken J, Porter MD, Pierson DL, Smith SM, Mergeay M, Leys N, Stefanyshyn-Piper HM, Gorie D, Nickerson CA. 2008. Media ion composition controls regulatory and virulence response of Salmonella in spaceflight. PLoS One 3:e3923.

10. Nickerson CA, Ott CM, Wilson JW, Ramamurthy R, Pierson DL. 2004. Microbial responses 
to microgravity and other low-shear environments. Microbiol Mol Biol Rev 68:345-361.

513 11. Schwarz RP, Goodwin TJ, Wolf DA. 1992. Cell culture for three-dimensional modeling in 514 rotating-wall vessels: an application of simulated microgravity. J Tissue Cult Methods $14: 51-57$.

12. Fang A, Pierson DL, Koenig DW, Mishra SK, Demain AL. 1997. Effect of simulated microgravity and shear stress on microcin B17 production by Escherichia coli and on its

13. Demain AL, Fang A. 2001. Secondary metabolism in simulated microgravity. Chem Rec $1: 333-346$.

14. Castro SL, Nelman-Gonzalez M, Nickerson CA, Mark Ott C. 2011. Induction of AttachmentIndependent Biofilm Formation and Repression of hfq Expression by Low-Fluid-Shear Culture of Staphylococcus aureus. Appl Environ Microbiol 77:6368-6378.

524 15. Wang H, Yan Y, Rong D, Wang J, Wang H, Liu Z, Wang J, Yang R, Han Y. 2016. Increased biofilm formation ability in Klebsiella pneumoniae after short-term exposure to a simulated microgravity environment. Microbiologyopen 5:793-801. 
533

534

535

536

537

538

539

540

541

542

543

544

545

546

547

548

549

550

551

552

553

18. Jones BW, Nishiguchi MK. 2004. Counterillumination in the Hawaiian bobtail squid, Euprymna scolopes Berry (Mollusca: Cephalopoda). Mar Biol 144:1151-1155.

19. Koropatnick TA, Engle JT, Apicella MA, Stabb EV, Goldman WE, McFall-Ngai MJ. 2004. Microbial factor-mediated development in a host-bacterial mutualism. Science 306:11861188.

20. Mandel MJ, Wollenberg MS, Stabb EV, Visick KL, Ruby EG. 2009. A single regulatory gene is sufficient to alter bacterial host range. Nature 458:215-218.

21. Mandel MJ, Schaefer AL, Brennan CA, Heath-Heckman EAC, Deloney-Marino CR, McFallNgai MJ, Ruby EG. 2012. Squid-derived chitin oligosaccharides are a chemotactic signal during colonization by Vibrio fischeri. Appl Environ Microbiol 78:4620-4626.

22. Brooks JF 2nd, Mandel MJ. 2016. The histidine kinase BinK Is a negative regulator of biofilm formation and squid colonization. J Bacteriol 198:2596-2607.

23. Foster JS, Kerney KR, Parrish ML, Khodadad CLM, Ahrendt SR. 2011. Potential of the Euprymna/Vibrio symbiosis as a model to assess the impact of microgravity on bacteriainduced animal development. Gravitational and Space Research 25:44-47.

24. Brooks JF 2nd, Gyllborg MC, Cronin DC, Quillin SJ, Mallama CA, Foxall R, Whistler C, Goodman AL, Mandel MJ. 2014. Global discovery of colonization determinants in the squid symbiont Vibrio fischeri. Proc Natl Acad Sci U S A 111:17284-17289.

25. Goodman AL, McNulty NP, Zhao Y, Leip D, Mitra RD, Lozupone CA, Knight R, Gordon Jl. 2009. Identifying genetic determinants needed to establish a human gut symbiont in its habitat. Cell Host Microbe 6:279-289. 
554 26. Goodman AL, Wu M, Gordon Jl. 2011. Identifying microbial fitness determinants by insertion sequencing using genome-wide transposon mutant libraries. Nat Protoc 6:1969_ 1980.

27. Dunn AK, Millikan DS, Adin DM, Bose JL, Stabb EV. 2006. New rfp- and pES213-derived tools for analyzing symbiotic Vibrio fischeri reveal patterns of infection and lux expression in situ. Appl Environ Microbiol 72:802-810.

28. Thompson LR, Nikolakakis K, Pan S, Reed J, Knight R, Ruby EG. 2017. Transcriptional characterization of Vibrio fischeri during colonization of juvenile Euprymna scolopes. Environ Microbiol 19:1845-1856.

29. Meeske AJ, Riley EP, Robins WP, Uehara T, Mekalanos JJ, Kahne D, Walker S, Kruse AC, Bernhardt TG, Rudner DZ. 2016. SEDS proteins are a widespread family of bacterial cell wall polymerases. Nature 537:634-638.

30. Joyce AR, Reed JL, White A, Edwards R, Osterman A, Baba T, Mori H, Lesely SA, Palsson BØ, Agarwalla S. 2006. Experimental and computational assessment of conditionally essential genes in Escherichia coli. J Bacteriol 188:8259-8271.

569 31. Casutt MS, Schlosser A, Buckel W, Steuber J. 2012. The single NqrB and NqrC subunits in the $\mathrm{Na}^{+}$-translocating $\mathrm{NADH}$ : quinone oxidoreductase $\left(\mathrm{Na}^{+}-\mathrm{NQR}\right)$ from Vibrio cholerae each

572 32. Steuber J, Halang P, Vorburger T, Steffen W, Vohl G, Fritz G. 2014. Central role of the $\mathrm{Na}^{+}-$ 573 translocating $\mathrm{NADH}$ :quinone oxidoreductase $\left(\mathrm{Na}^{+}-\mathrm{NQR}\right)$ in sodium bioenergetics of Vibrio $574 \quad$ cholerae. Biol Chem 395:1389-1399. 
33. Aeckersberg F, Lupp C, Feliciano B, Ruby EG. 2001. Vibrio fischeri outer membrane protein OmpU plays a role in normal symbiotic colonization. J Bacteriol 183:6590-6597.

577 34. Turner KH, Everett J, Trivedi U, Rumbaugh KP, Whiteley M. 2014. Requirements for Pseudomonas aeruginosa acute burn and chronic surgical wound infection. PLoS Genet 10:e1004518.

35. Langmead B, Trapnell C, Pop M, Salzberg SL. 2009. Ultrafast and memory-efficient alignment of short DNA sequences to the human genome. Genome Biol 10:R25.

36. Reback J, McKinney W, jbrockmendel, Van den Bossche J, Augspurger T, Cloud P, 2020. pandas-dev/pandas: Pandas 1.1.0.

37. McKinney W, Others. 2010. Data structures for statistical computing in python, p. 51-56. In Proceedings of the 9th Python in Science Conference. Austin, TX.

38. Love MI, Huber W, Anders S. 2014. Moderated estimation of fold change and dispersion for RNA-seq data with DESeq2. Genome Biol 15:550.

39. Lyell NL, Dunn AK, Bose JL, Vescovi SL, Stabb EV. 2008. Effective Mutagenesis of Vibrio fischeri by Using Hyperactive Mini-Tn5 Derivatives. Appl Environ Microbiol 74:7059-7063. requires tfoX and tfoY. Environ Microbiol 12:2302-2311. 
sepiolid squid Euprymna scolopes. J Bacteriol 172:3701-3706.

597 42. Mandel MJ, Stabb EV, Ruby EG. 2008. Comparative genomics-based investigation of resequencing targets in Vibrio fischeri: focus on point miscalls and artefactual expansions. BMC Genomics 9:138.

600 43. Brooks JF 2nd, Gyllborg MC, Kocher AA, Markey LEH, Mandel MJ. 2015. TfoX-based genetic mapping identifies Vibrio fischeri strain-level differences and reveals a common lineage of laboratory strains. J Bacteriol 197:1065-1074.

44. Post DMB, Yu L, Krasity BC, Choudhury B, Mandel MJ, Brennan CA, Ruby EG, McFallNgai MJ, Gibson BW, Apicella MA. 2012. O-antigen and core carbohydrate of Vibrio fischeri lipopolysaccharide: composition and analysis of their role in Euprymna scolopes light organ colonization. J Biol Chem 287:8515-8530.

607 45. Studer SV, Mandel MJ, Ruby EG. 2008. AinS quorum sensing regulates the Vibrio fischeri acetate switch. J Bacteriol 190:5915-5923. 
bioRxiv preprint doi: https://doi.org/10.1101/2020.08.13.250431; this version posted August 14,2020 . The copyright holder for this preprint (which was not certified by peer review) is the author/funder, who has granted bioRxiv a license to display the preprint in perpetuity. It is made available under aCC-BY-NC-ND 4.0 International license.

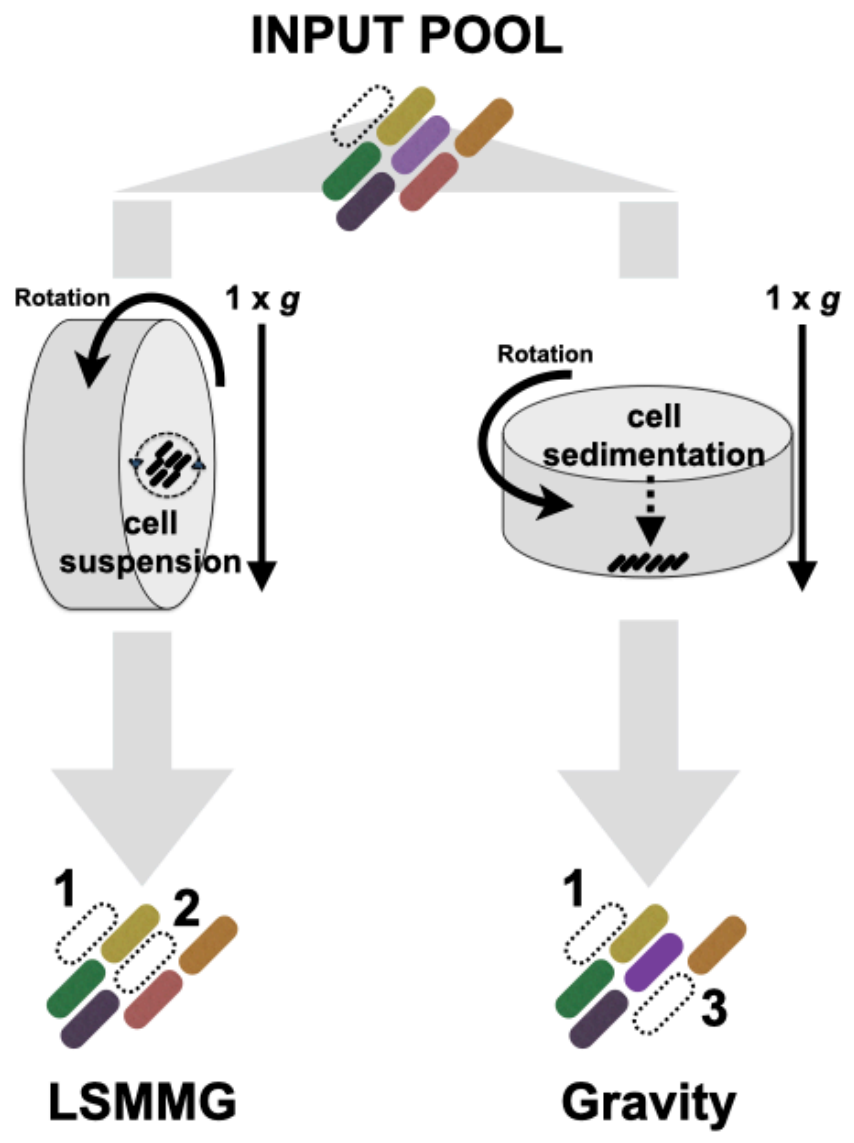


bioRxiv preprint doi: https://doi.org/10.1101/2020.08.13.250431; this version posted August 14, 2020. The copyright holder for this preprint (which was not certified by peer review) is the author/funder, who has granted bioRxiv a license to display the preprint in perpetuity. It is made available under aCC-BY-NC-ND 4.0 International license.

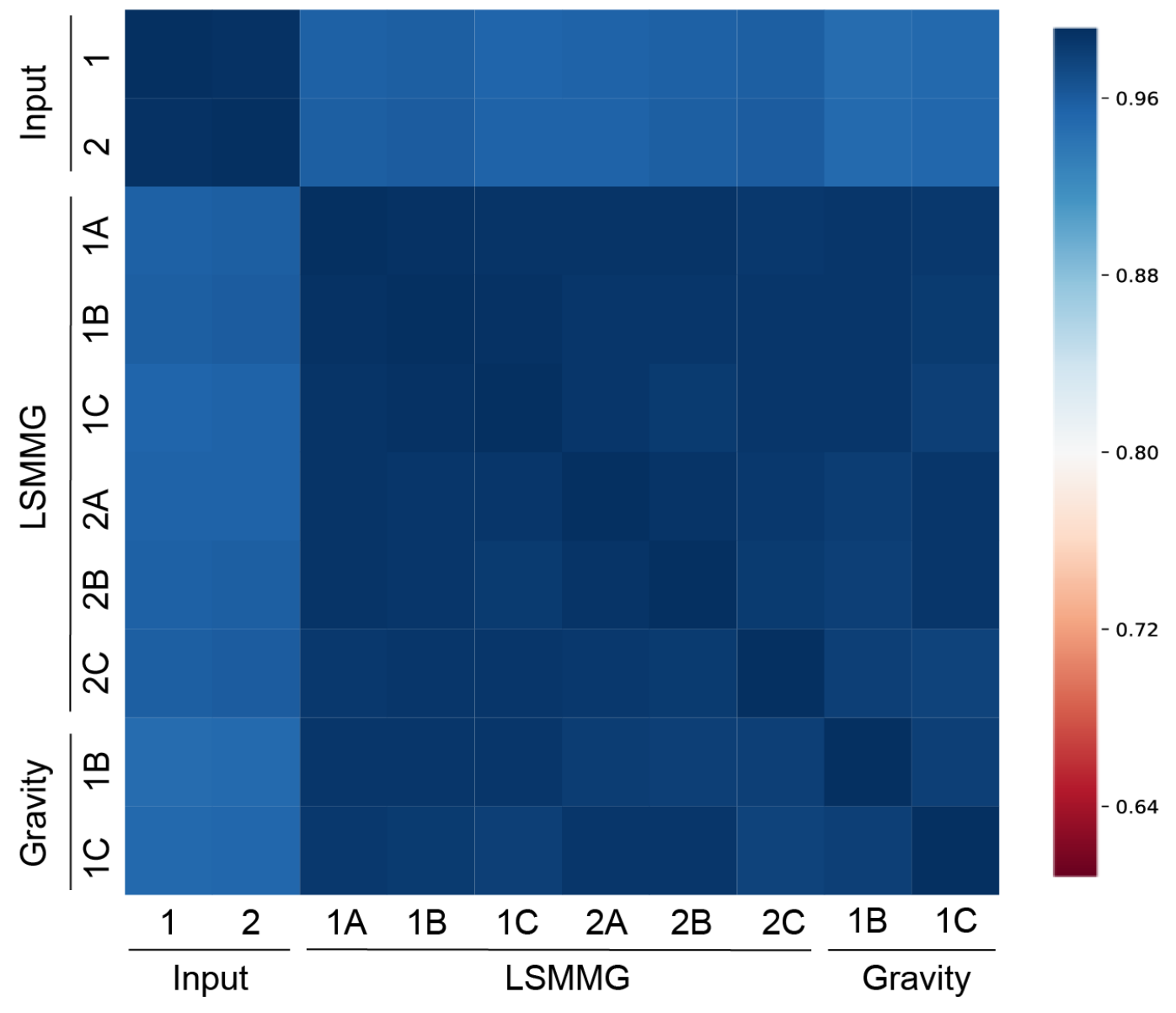


bioRxiv preprint doi: https://doi.org/10.1101/2020.08.13.250431; this version posted August 14, 2020. The copyright holder for this preprint (which was not certified by peer review) is the author/funder, who has granted bioRxiv a license to display the preprint in perpetuity. It is made available under aCC-BY-NC-ND 4.0 International license.

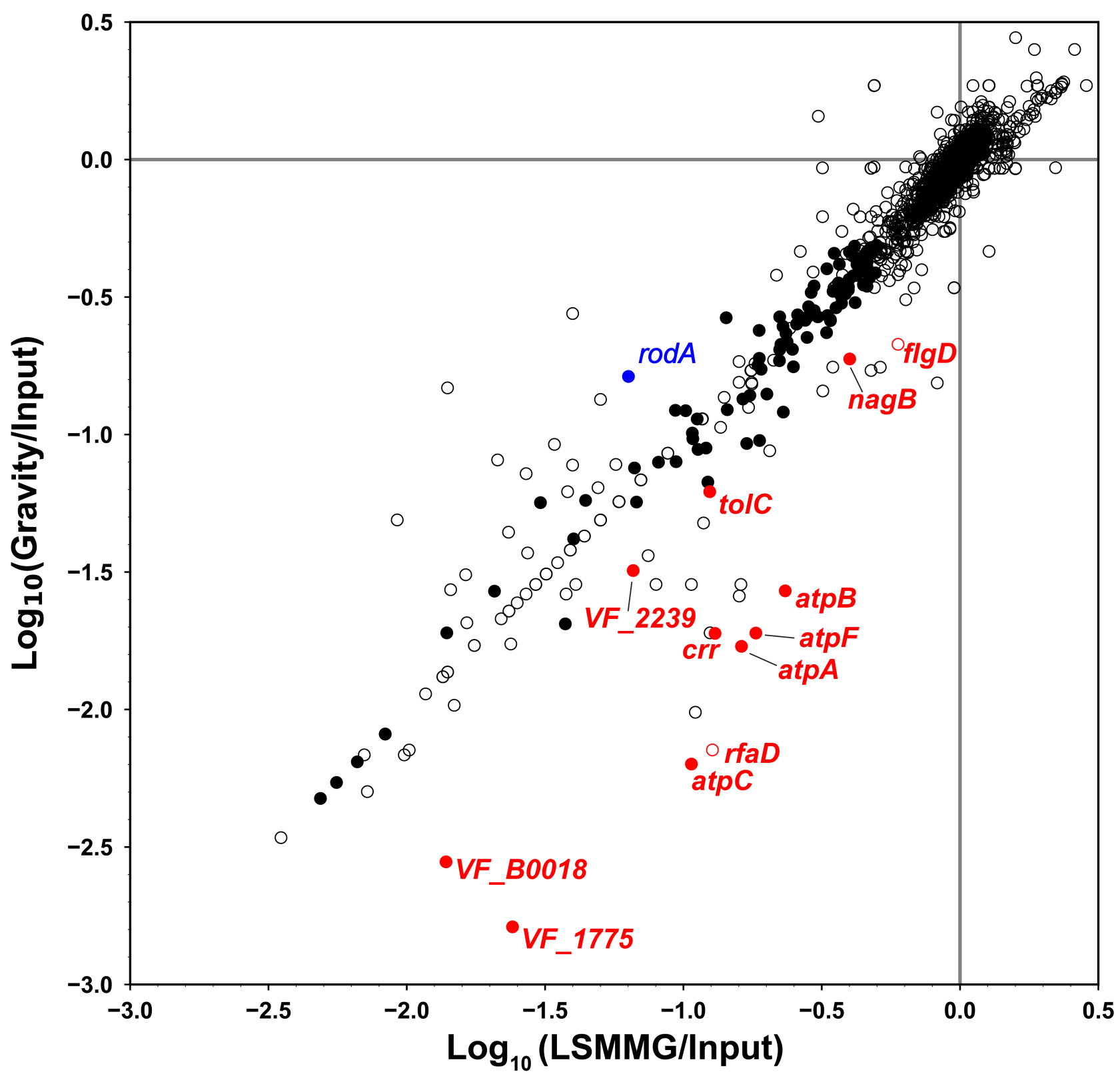


bioRxiv preprint doi: https://doi.org/10.1101/2020.08.13.250431; this version posted August 14,2020 . The copyright holder for this preprint (which was not certified by peer review) is the author/funder, who has granted bioRxiv a license to display the preprint in perpetuity. It is made available under aCC-BY-NC-ND 4.0 International license.

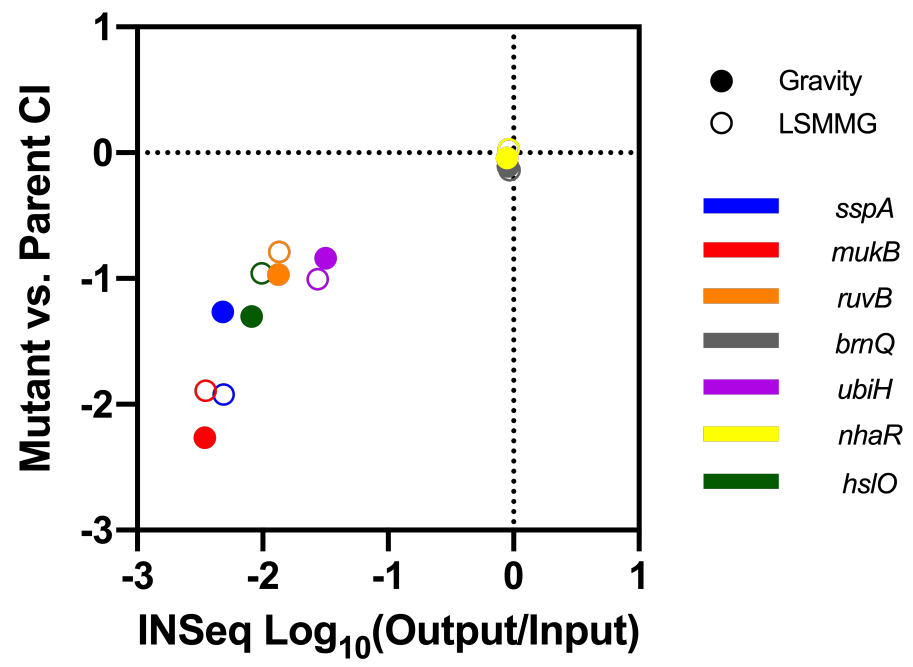



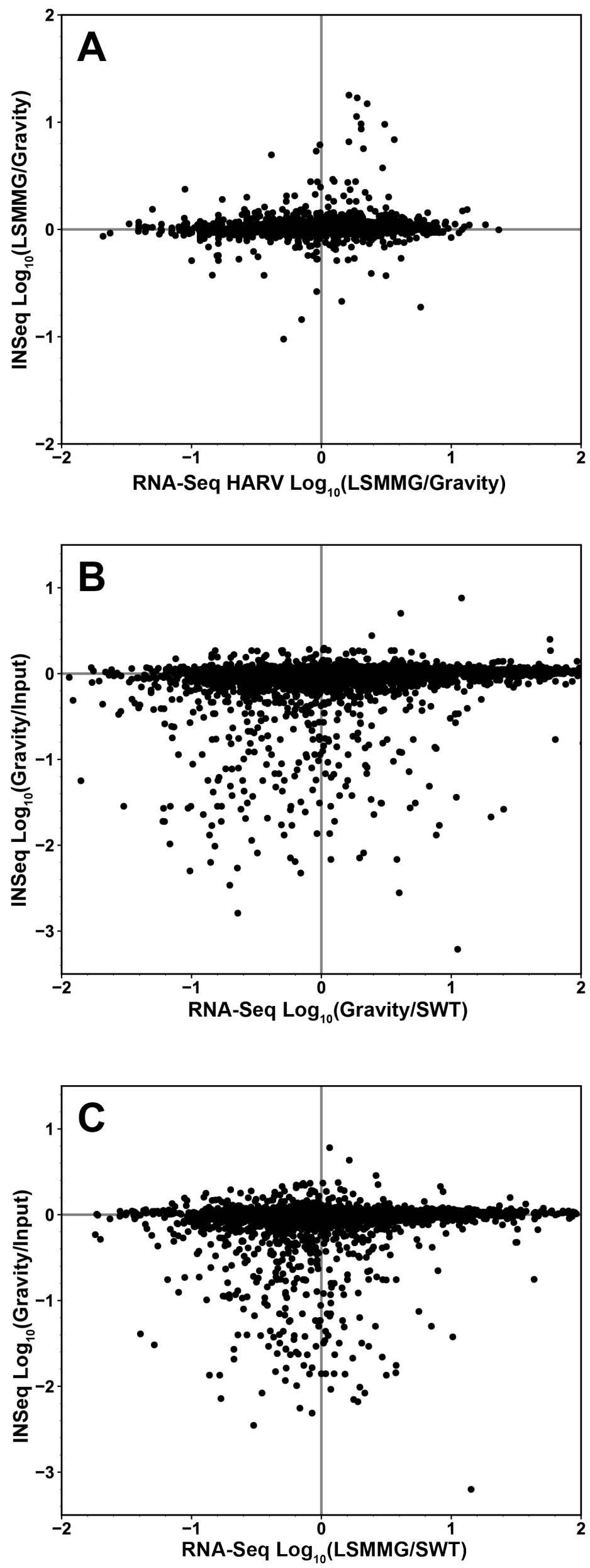